\title{
SATB1 is Correlated with Progression and Metastasis of Breast Cancers: A Meta- Analysis
}

\author{
Zhongya Pan Wei Jing Keli He Li Zhang Xinghua Long \\ Zhongnan Hospital of Wuhan University, Wuhan, China
}

\section{Key Words}

SATB1 • Breast Cancer • Metastasis • Prognosis

\begin{abstract}
Background/Aims: Several researches have evaluated the significance of SATB1 (Special ATrich sequence binding protein 1 ) expression in breast cancers (BCs), but the results have been disputed, especially in the aspects of clinicopathological features and prognosis. Therefore, our study aimed to use a meta-analysis to summarize the clinical and prognostic relevance of SATB1 gene expression in BCs. Methods: A literature search of PubMed, EMBASE, Cochrane library, Chinese Wanfang and CNKI was performed to identify eligible studies. Ten studies total, comprising 5,185 patients (1,699 SATB1-positive and 3,486 SATB1-negative), were enrolled in our study, which was performed using Revman5.3 Software and Stata11.0 Software. Results: This meta-analysis showed that the expression of SATB1 was significantly higher in breast cancer than in normal tissues $(\mathrm{OR}=12.28 ; 95 \% \mathrm{CI}=6.01-25.09)$, and was statistically related to several clinicopathological parameters, including lymph node metastasis $(\mathrm{OR}=1.55,95 \% \mathrm{CI}=$ 1.01-2.39) and Tumor Node Metastasis(TNM) stage ( $\mathrm{OR}=0.35,95 \% \mathrm{CI}=0.22-0.56)$. However, the level of SATB1 was not statistically associated with the age $(\mathrm{OR}=1.13,95 \% \mathrm{CI}=0.87-1.46)$, tumour size $(O R=0.72,95 \% C I=0.44-1.19)$, estrogen receptor $(O R=0.78,95 \% C I=0.55-1.09)$, progesterone receptor $(\mathrm{OR}=0.64,95 \% \mathrm{CI}=0.32-1.29)$, $\mathrm{HER} 2$ status $(\mathrm{OR}=1.98,95 \% \mathrm{CI}=0.74-$ $5.30)$, and histological type $(\mathrm{OR}=0.49,95 \% \mathrm{CI}=0.22-1.11)$. Conclusion: High expression of SATB1 was significantly correlated with tumourigenesis and metastasis of BCs, indicating poor prognosis for patients. SATB1 could serve as a potential marker for detection and prognosis evaluation of breast cancers.
\end{abstract}

Z. Pan and W. Jing contributed equally to this work. 


\section{Introduction}

Cancers have the highest mortality rates among various diseases in developed countries [1]. The global incidence of breast cancer has been on the rise since the late 1970's, Currently, breast cancer (BC) is one of the most common cancers among women in the world, accounting for $23 \%$ of tumours in females [2]. With the development of molecular biology, researchers have been paying increasing attention to biological markers associated with metastasis and recurrence of breast cancers. Despite advances in early detection through mammography screening, there are still multiple hurdles in the early diagnosis and accurate prognosis evaluation of breast cancers [3]. Therefore, there is an urgent need to identify sensitive and specific molecular markers to predict breast cancer tumourigenesis and metastasis.

The special AT-rich region binding protein 1 (SATB1) is a nuclear matrix attachment regions (MARs)-binding protein that forms a docking site for chromatin-modifying enzymes and transcription activators or repressors. As a potent epigenetic regulator, SATB1 may affect the transcription of numerous genes [4, 5]. Jacob Elebro et al. [6] indicated that tumors with higher expression of SATB1 were a more aggressive tumour phenotype and might result in a shorter overall survival of patients for diverse cancers, including BCs, colorectal cancers, gastric cancers and gliomas. SATB1 expression was associated with cell development, proliferation and differentiation in this study [7]. Additionally, SATB1 appears to interact with the BCL2 gene and partly regulate BCL2 expression, which that is crucial in the regulation of apoptosis [8]. In breast cancer cells, SATB1 inhibited the tumour metastasis suppressor genes BRMS1 and KAI1 [9]. Neill Patani et al. [10] showed that SATB1 mRNA expression was significantly associated with positive estrogen receptor $\left(\mathrm{ER}^{+}\right)$status and poor prognostic parameters, including increasing tumour grade, TNM stage and the Nottingham Prognostic Index (NPI). Furthermore, breast cancer cells with increased SATB1 expression acquired a metastatic phenotype [11]. Interestingly, a recent study illustrated that knockdown of SATB1 inhibited cell invasion and proliferation [12]. Kohwi-Shigematsu et al. [13] demonstrated that there were obvious difference in levels of SATB1 protein or mRNA between nontumourigenic and aggressive breast cancer cell lines. Consequently, silencing SATB1 in BC with high expression of this protein may open a new target for BC therapy.

The relationships between SATB1 and clinicopathological features in BC patients have been reported in many studies. However, most research studies have had limited power to explore the association between SATB1 expression and BCs patients' clinicopathological parameters due to small sample sizes. Meanwhile, a previous study reported that SATB1 expression did not promote breast cancer progression and was not associated with breast cancer outcomes [14]. Therefore, we conducted a meta-analysis to evaluate the prognostic value of SATB1 in BCs with a larger sample size of patients.

\section{Materials and Methods}

\section{Literature search}

We searched the PubMed, EMBASE, Cochrane library, Chinese Wanfang and CNKI databases for studies published through January 2016, with the following keywords: SATB1 and breast cancers or Special AT-rich sequence binding protein 1 and breast cancer; prognosis and overall survival. In addition, all references in these eligible studies were examined to identify additional literature that had not been retrieved from the databases in order to discover additional relevant publications.

\section{Inclusion Criteria}

Eligible studies in this meta-analysis met the following standards: the studies were related to breast cancers and the SATB1 gene, the patients in the studies were females who were pathologically diagnosed with breast cancers, the studies were of case-control design, and the studies contained sufficient published data available for calculating an odds ratio (OR) and 95\% confidence interval (CI). If there were duplicated data, we chose the study with the most complete data or the most recent study. 


\section{Cellular Physiology Cell Physiol Biochem 2016;38:1975-1983 \\ \begin{tabular}{l|l|l} 
DOI: 10.1159/000445558 & $\begin{array}{l}\text { C) 2016 The Author(s). Published by S. Karger AG, Basel } \\
\text { www.karger.com/cpb }\end{array}$
\end{tabular} \\ Pan et al.: SATB1 is Correlated with Progression of Breast Cancer}

\section{Exclusion Criteria}

The exclusion criteria included the following types of publications: studies with repeated data; reviews, case reports, letters and conference abstracts; studies in which the number of patients with SATB1-positive or SATB1-negative could not be provided; and studies lacking original data.

\section{Data Extraction}

The relevant information of each eligible study was extracted independently by two researchers (Pan and Jing), which included, the authors, year of publication, study origin, study objects, measuring method, clinical stage as well as other relevant factors.

\section{Statistical Analysis}

The pooled ORs and 95\%CIs were used to assess the relationships between SATB1 expression and breast cancers. The survival outcomes of breast cancer patients with SATB1 expression were evaluated by ORs and 95\%CIs. The clinicopathological features included age, tumour size, lymph node status, histological type, TNM stage, and hormone estrogen receptor (ER), progesterone receptor (PR) and HER2 status. The ORs and 95\%CIs were also used to evaluate the associations of SATB1 with clinic pathological factors of breast tumours. We divided the clinicopathological factor of age the two following ranges: $\leq 50$ and $>50$ years of age. For tumour size, sample were divided according to whether they were $\leq 2 \mathrm{~cm}$ or $>2 \mathrm{~cm}$ in size. Similarly, histological types included IDC (Infiltrating Ductal Carcinoma) and other types. In accordance with the American Joint Committee on Cancer (AJCC) staging system [15], the patients were separated into TNM stages: those that were early-stage ( $\leq$ II ) and those that were late-stage ( $\geq$ III). As for histological grade, grade $\leq$ II and grade $\geq$ III were assigned as low-grade and high-grade, respectively. The Revman5.3 Software, which was recommended by Cochrane Collaboration, was used to perform the meta-analysis and evaluate heterogeneity between studies by Cochrane Q-test and P-values. If heterogeneity was absent $\left(I^{2} \leq 50 \%\right.$ or $P \geq 0.05$ ), a fixed-effect model was used to calculate pooled ORs. If not, the random-effect model was more appropriate and was employed to calculate the ORs [16]. In addition, the $I^{2}$-test put forward by Higgins and Thompson was used to accurately evaluate the degree of heterogeneity [17]. Sensitivity analysis and publication bias were performed by using Stata11.0 Software. Publication bias was evaluated by Begg's test, and a significance of $P>0.05$ was considered to denote no deviation among publications.

\section{Result}

Included studies and characteristics

Ninety-three articles were identified by our search, of which 45 records were identified through PubMed and 49 records were from other sources. After the titles and abstracts were reviewed, 71 duplicate and irrelevant articles were removed. After carefully reading the fulltext articles, the following 12 papers were removed: 5 review articles and 7 papers that did not have sufficient data for further analysis. Consequently, 10 published articles were eligible for our meta-analysis [7, 11, 18-25].

Table 1 summarized the main characteristics of the included 10 studies ranging from 2008 to 2015. All of the patients were divided into 2 groups, Asian and Caucasian. Immu-

Table 1. Characteristics of studies included in this meta-analysis for SATB1. NA: Not available; IB: Immunoblotting; IHC: Immunohistochemistry

\begin{tabular}{|c|c|c|c|c|c|c|c|}
\hline First author & Year & Ethnic & Clinical stage & Method & SATB1-positive & SATB1-negative & Dilution \\
\hline Liu X [7] & 2015 & Asian & I-IV & IHC & 92 & 77 & NA \\
\hline Zhang S [22] & 2015 & Asian & I-III & IHC & 81 & 30 & NA \\
\hline Hanker LC [11] & 2011 & Caucasian & NA & Microarray & 283 & 2747 & $1: 100$ \\
\hline Laurinavicius A [19] & 2012 & Caucasian & NA & IHC & 57 & 52 & $1: 200$ \\
\hline Han HJ [18] & 2008 & Caucasian & $\mathrm{NA}$ & IB/ Microarray & 875 & 443 & NA \\
\hline Zhang Y [23] & 2015 & Asian & I-IV & IHC & 39 & 12 & $1: 200$ \\
\hline Zhuang JL [25] & 2010 & Asian & I-III & IHC & 57 & 27 & NA \\
\hline Zhang Y [24] & 2014 & Asian & I-IV & IHC & 28 & 11 & NA \\
\hline Tan XH [20] & 2012 & Asian & NA & IHC & 146 & 56 & NA \\
\hline Yang WH [21] & 2015 & Asian & I-III & IHC & 41 & 31 & $1: 100$ \\
\hline
\end{tabular}


Fig. 1. (A) Forest plot for evaluating the association between SATB1 gene expression and breast cancer risk; B-I. Forrest plot of ORs for the association of SATB1 expression with the (B) age; (C) tumour size; (D) lymph node metastasis; (E) TNM; (F) ER status; (G) PR status; (H) HER2 status; (I) histological type.

nohistochemistry (IHC), microarrays and Immunoblotting (IB) were the methods used to assess SATB1 expression in $\mathrm{BC}$ tissues.

Relationships between SATB1 expression and clinicopathological parameters

Ten studies enrolling 5,185 participants, in which 1699 patients were SATB1-positive and 3,486 patients were SATB1-negative, showed that high expression of SATB1 was positively correlated with breast cancer progression $\mathrm{OOR}=12.28,95 \% \mathrm{CI}$ $=6.01-25.09, P<0.00001$, random-effect) (Fig. 1A). Furthermore, the SATB1 expression was significantly related to several clinicopathological parameters, including lymph node metastasis $(\mathrm{OR}=1.55,95 \% \mathrm{CI}=1.01$ 2.39, $P=0.05$, random-effect), and TNM stage $(\mathrm{OR}=0.35,95 \% \mathrm{CI}=0.22$ $0.56, P<0.0001$, fixed-effect) (Fig. 1D, E). However, SATB1 expression was not associated with the age of patients $(\mathrm{OR}=1.13,95 \% \mathrm{CI}=0.87-1.46, P$ $=0.36$, fixed-effect), tumour size (OR $=0.72,95 \% \mathrm{CI}=0.44-1.19, P=0.20$, random-effect), ER (OR $=0.78,95 \% \mathrm{CI}$ $=0.55-1.09, P=0.14$, fixed-effect ), HER2 (OR $=1.98,95 \% \mathrm{CI}=0.74-5.30$, $P=0.17$, random-effect), PR status $(\mathrm{OR}=0.64,95 \% \mathrm{CI}=0.32-1.29, P=$ 0.21 , random-effect), and histological type $(\mathrm{OR}=0.49,95 \% \mathrm{CI}=0.22-1.11, P$ $=0.09$, random-effect) (Fig. 1B-C, F-I).

\section{Sensitivity analysis}

To assess whether the individual studies affected the overall results, we conducted a sensitivity analysis using Stata11.0 software. The results indicated that each individual study

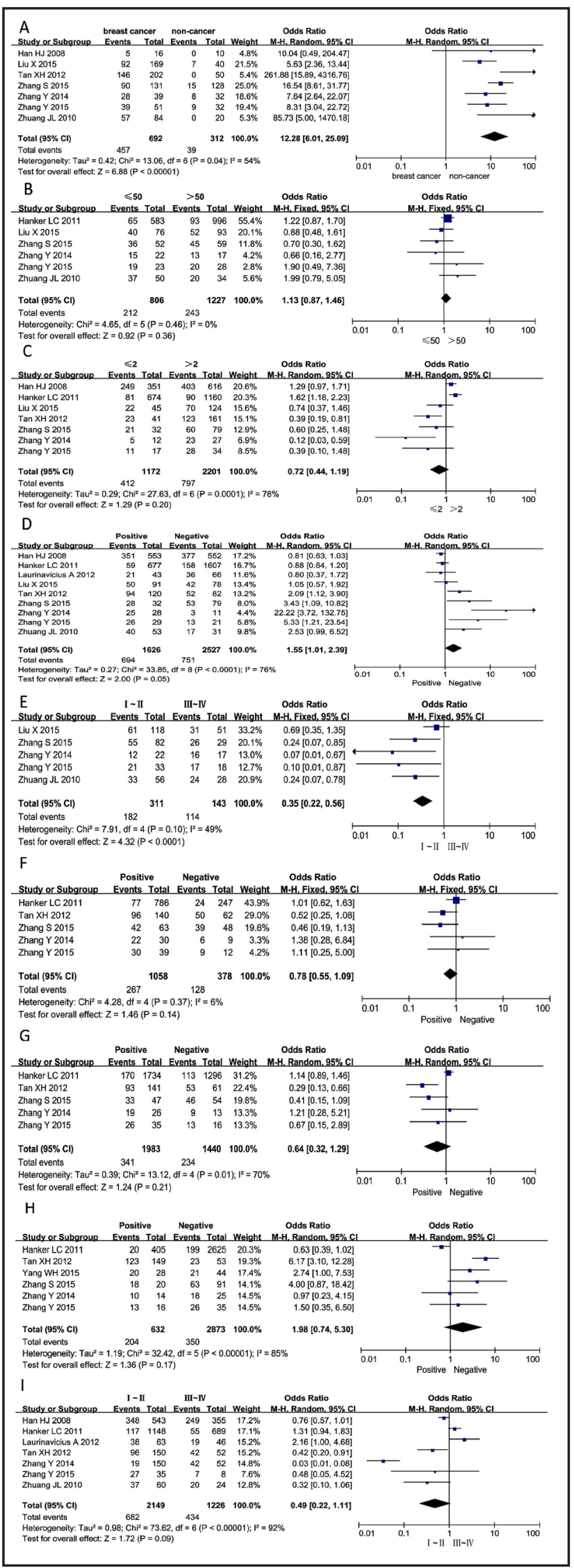




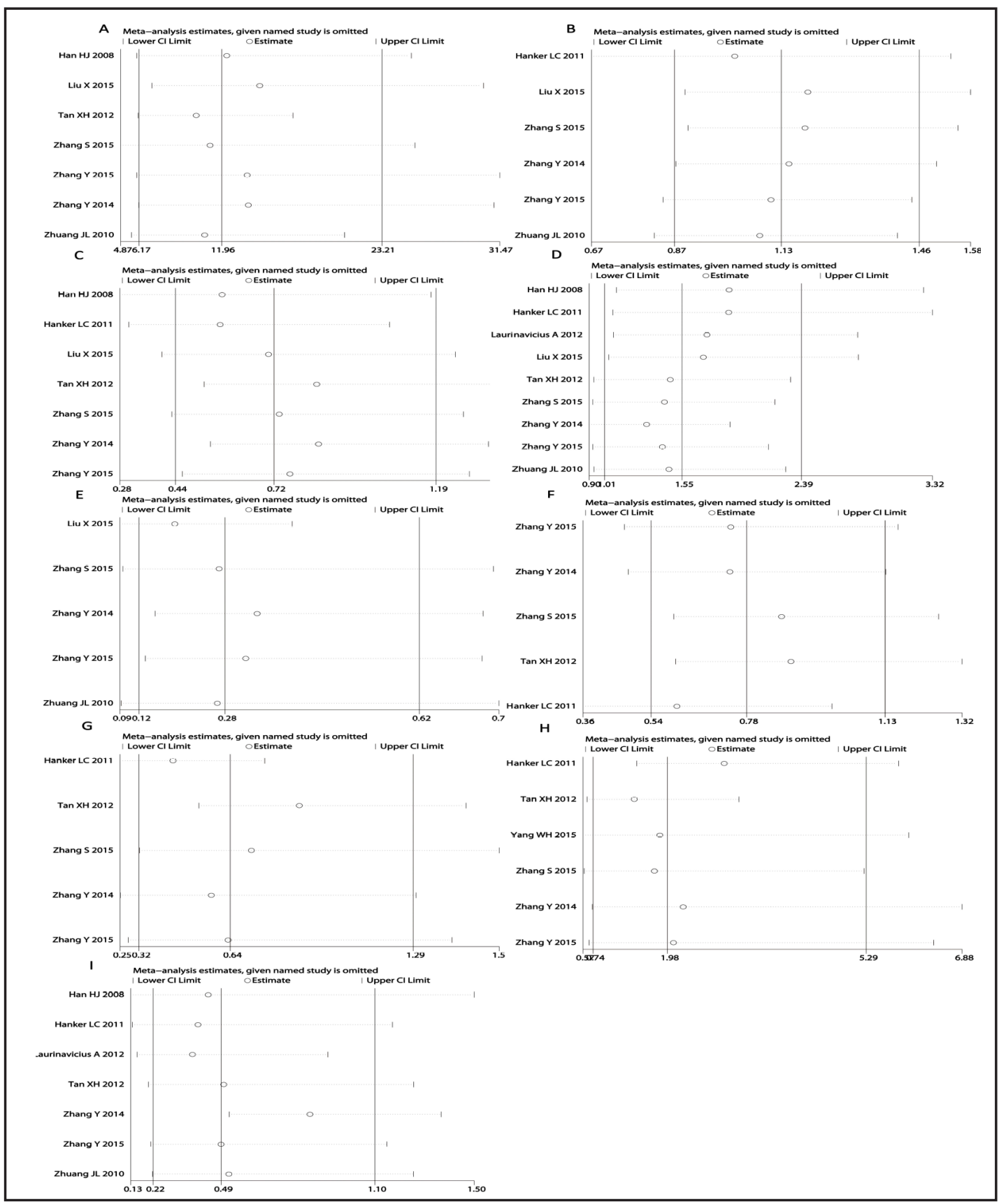

Fig. 2. (A) Sensitivity analyses of the study that SATB1 gene expression and breast cancer risk; B-I. Sensitivity analyses of the studies (B) age; (C) tumour size; (D) lymph node metastasis; (E) TNM; (F) ER status; (G) PR status; (H) HER2 status; (I) histological type.

had little impact on the final results (Fig. 2A-I), which demonstrated that our analyses of clinicopathological parameters were relatively stable and credible.

\section{Publication bias}

Publication bias was evaluated by Begg's test (Fig. 3A-I). In our study, values of $P>$ 0.05 in the Begg's test suggested an absence of publication bias in the articles related to clinicopathological parameters, including TNM stage, HER2 status, age, tumour size, histological type, ER and PR. However, there was a publication bias in the subgroup of lymph node metastasis $(P=0.009)$ (Fig. 3D). 


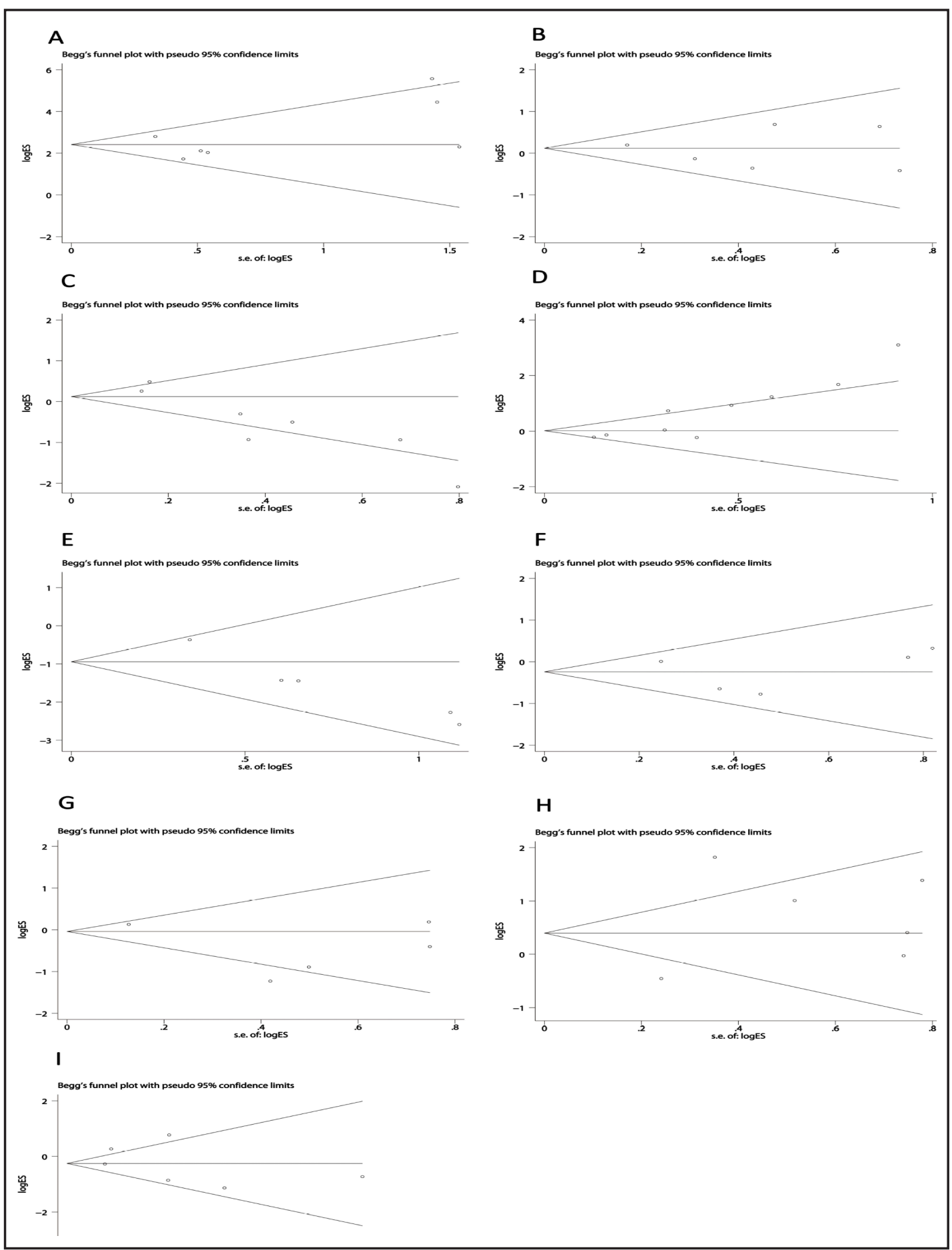

Fig. 3. Begg's test for publication bias. A publication bias of the study that SATB1 gene expression and breast cancer risk; B-I. publication bias of the studies (B) age; (C) tumour size; (D) lymph node metastasis; (E) TNM; (F) ER status; (G) PR status; (H) HER2 status; (I) histological type.

\section{Discussion}

Breast cancer is the most common type of malignancy in females. While early-stage breast cancer is normally associated with a good prognosis [26], a considerable number of patients are predicted to have a limited lifespan because of distant metastases. The KARGER 


\section{Cellular Physiology Cell Physiol Biochem 2016;38:1975-1983 \\ \begin{tabular}{l|l|l}
\hline DOI: 10.1159/000445558 & $\begin{array}{l}\text { (c) 2016 The Author(s). Published by S. Karger AG, Basel } \\
\text { www.karger.com/cpb }\end{array}$
\end{tabular} \\ Pan et al.: SATB1 is Correlated with Progression of Breast Cancer}

expression of SATB1 has been demonstrated to correlate with reduced overall survival in breast cancer patients [18]. Recently, studies have suggested that SATB1 played a crucial role in the metastatic process of breast cancers [27]. In this meta-analysis, we illustrated that high expression of SATB1 was positively correlated with breast cancer risk, especially with breast cancer metastasis.

Recently, many studies indicated that SATB1 has an abnormally high expression in a variety of tumour cells, affecting the promotion of tumour growth and metastasis. Han et al. [18] reported that SATB1 expression was significantly higher in poorly differentiated tissues. Additionally, the SATB1 protein played an important role in early differentiation, cell homeostasis and responses to a number of types of stimulation [27, 28]. Meanwhile, researches elaborated that SATB1 acted as a 'master genome organizer' in human breast carcinogenesis and SATB1 mRNA expression was associated with poor prognostic parameters, including increasing tumour grade, TNM stage and NPI (Nottingham Prognostic Index) $[10,29]$. Thus, SATB1 could be considered as a potential prognostic factor for breast cancer.

The most important reason for the low 5-year survival rate is the occurrence of distant metastases evaluated by lymph node metastasis. Recently, studies suggested that SATB1dependent genes regulated the genes that are known to promote either bone [30] or lung [31] metastasis in MDA-MB-231 cells. The development of breast tumours involved the regulation of various molecules, including SATB1, Notch1 and Snail1. In 2015, Sun et al. [12] indicated that overexpression of SATB1 in MCF-7 cells increased the expression levels of Notch1 and Snail1. These studies demonstrated that the expression of SATB1 may increase the size of the breast cancer stem cell (BCSC) population via the activation of Notch signaling, which was required for increased expression of Snail1. Meanwhile, Yuan et al. [32] indicated that higher expression of Notch signaling was associated with a greater possibility of lymph node metastasis (LNM) and higher TNM stages. Notably, previous studies have suggested that the activation of Notch promoted the expansion of BCSCs and was associated with the development and progression of breast cancer [33, 34]. Breast cancer cells have also been hypothesized to acquire stem cell-like properties associated with EMT [35], for which snail1 activity is required [36]. Thus, SATB1 might be used to predict the occurrence of tumour metastasis.

In our meta-analysis, we evaluated the relationship between the expression of SATB1 and TNM stage in BC. We found that TNM stage was associated with the expression of SATB1, which indicated its utility in predicting the likelihood of disease progression in patients with early-stage breast cancer. Gao et al. [37] demonstrated that knockdown of SATB1 in highly aggressive MDA-MB-231 cancer cells reversed tumourigenesis and inhibited tumour growth and metastasis in vitro. Therefore, SATB1 can serve as a sentinel, indicating that cells have acquired the aggressive phenotype.

Studies have also demonstrated that SATB1 expression was significantly related to clinicopathological parameters. The levels of SATB1 expression were correlated with tumour size [24] as well as HER2 [7], ER and PR [25] status in breast cancer. Han et al. [18] found that SATB1 was a prognostic factor, which was independent of histological type. However, our subgroup analysis showed that SATB1 expression was not associated with age, tumour size, histological type, ER, PR and HER2 status. Considering the limited sample size in eligible studies, we cannot draw a definitive conclusion concerning the relationships between SATB1 and these clinicopathological parameters. Therefore, more studies with larger sample sizes are needed for further study.

There are several limitations in our study. First, different methods were used to assess SATB1 expression in the eligible studies, and these differences might have a great impact on the results. Second, most of the included studies reported positive results because those with negative results are generally less likely to be published, which may be the cause of publication bias in the subgroup of lymph node metastasis. Third, not all of our studies were based on case-control studies, which may affect the quality of this meta-analysis. Finally, the results of subgroups may be affected due to the limited number of studies. 


\begin{tabular}{|c|c|c|}
\hline Cellular Physiology & Cell Physiol Biochem 2016; & 38:1975-1983 \\
\hline and Biochemistry & $\begin{array}{l}\text { DOI: } 10.1159 / 000445558 \\
\text { Published online: May } 09,2016\end{array}$ & $\begin{array}{l}\text { O } 2016 \text { The Author(s). Published by S. Karger AG, Basel } \\
\text { www.karger.com/cpb }\end{array}$ \\
\hline
\end{tabular}

\section{Conclusion}

This meta-analysis is the first one of its kind to evaluate the clinical and prognostic role of SATB1 expression in BC. We demonstrate that the expression of SATB1 is associated with TNM stage and lymph node metastasis, two factors that are associated with a reduced life expectancy in BC patients. In conclusion, our study demonstrated that SATB1 might be a novel predictive factor for assessing prognosis and therapeutic target in breast cancers.

\section{Acknowledgements}

The Project-sponsored by SRF for ROCS, SEM. This work was supported by grants from National Natural Science Foundation of China (nos. 30873044 and 81272372).

\section{Disclosure Statement}

The authors declare no conflicts of interest.

\section{References}

1 Siegel R, Ward E, Brawley O, Jemal A: Cancer statistics, 2011: the impact of eliminating socioeconomic and racial disparities on premature cancer deaths. CA Cancer J Clin 2011;61:212-236.

2 Ferlay J, Soerjomataram I, Dikshit R, Eser S, Mathers C, Rebelo M, Parkin DM, Forman D, Bray F: Cancer incidence and mortality worldwide: sources, methods and major patterns in GLOBOCAN 2012. Int J Cancer 2015;136:E359-386.

3 Elmore JG, Barton MB, Moceri VM, Polk S, Arena PJ, Fletcher SW: Ten-year risk of false positive screening mammograms and clinical breast examinations. N Engl J Med 1998;338:1089-1096.

4 Kowalczyk AE, Godlewski J, Krazinski BE, Kiewisz J, Sliwinska-Jewsiewicka A, Kwiatkowski P, Pula B, Dziegiel P, Janiszewski J, Wierzbicki PM, Kmiec Z: Divergent expression patterns of SATB1 mRNA and SATB1 protein in colorectal cancer and normal tissues. Tumour Biol 2015;36:4441-4452.

5 Liu J, Han P, Li M, Yan W, Liu J, Liu J, He J, Tu W, Xia Y, Zhou Z, Gong J, Liu M, Ding Q Tian D: The histidinerich calcium binding protein (HRC) promotes tumor metastasis in hepatocellular carcinoma and is upregulated by SATB1. Oncotarget 2015;6:6811-6824.

6 Elebro J, Heby M, Gaber A, Nodin B, Jonsson L, Fristedt R, Uhlen M, Jirstrom K, Eberhard J: Prognostic and treatment predictive significance of SATB1 and SATB2 expression in pancreatic and periampullary adenocarcinoma. J Transl Med 2014;12:289.

7 Liu X, Zheng Y, Qiao C, Qv F, Wang J, Ding B, Sun Y, Wang Y: Expression of SATB1 and HER2 in breast cancer and the correlations with clinicopathologic characteristics. Diagn Pathol 2015;10:50.

8 Gong F, Sun L, Wang Z, Shi J, Li W, Wang S, Han X, Sun Y: The BCL2 gene is regulated by a special AT-rich sequence binding protein 1-mediated long range chromosomal interaction between the promoter and the distal element located within the 3'-UTR. Nucleic Acids Res 2011;39:4640-4652.

9 Steeg PS: Metastasis suppressors alter the signal transduction of cancer cells. Nat Rev Cancer 2003;3:5563.

10 Patani N, Jiang W, Mansel R, Newbold R, Mokbel K: The mRNA expression of SATB1 and SATB2 in human breast cancer. Cancer Cell Int 2009;9:18.

11 Hanker LC, Karn T, Mavrova-Risteska L, Ruckhaberle E, Gaetje R, Holtrich U, Kaufmann M, Rody A, Wiegratz I: SATB1 gene expression and breast cancer prognosis. Breast 2011;20:309-313.

12 Sun Z, Zhang C, Zou X, Jiang G, Xu Z, Li W, Xie H: Special AT-rich sequence-binding protein-1 participates in the maintenance of breast cancer stem cells through regulation of the Notch signaling pathway and expression of Snail1 and Twist1. Mol Med Rep 2015;11:3235-3242.

13 Kohwi-Shigematsu T, Han HJ, Russo J, Kohwi Y: Re: The role of SATB1 in breast cancer pathogenesis. J Natl Cancer Inst 2010;102:1879-1880; author reply 80-81.

14 Iorns E, Hnatyszyn HJ, Seo P, Clarke J, Ward T, Lippman M: The role of SATB1 in breast cancer pathogenesis. J Natl Cancer Inst 2010;102:1284-1296. 


\section{Cellular Physiology Cell Physiol Biochem 2016;38:1975-1983

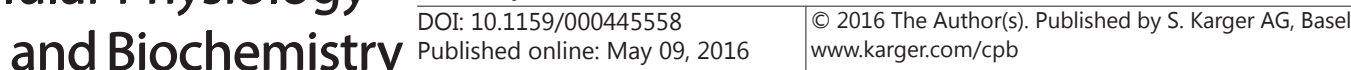 \\ Pan et al.: SATB1 is Correlated with Progression of Breast Cancer}

15 Singletary SE, Allred C, Ashley P, Bassett LW, Berry D, Bland KI, Borgen PI, Clark GM, Edge SB, Hayes DF, Hughes LL, Hutter RV, Morrow M, Page DL, Recht A, Theriault RL, Thor A, Weaver DL, Wieand HS, Greene FL: Staging system for breast cancer: revisions for the 6th edition of the AJCC Cancer Staging Manual. Surg Clin North Am 2003;83:803-819.

16 DerSimonian R, Laird N: Meta-analysis in clinical trials. Control Clin Trials 1986;7:177-188.

17 Higgins JP, Thompson SG, Deeks JJ, Altman DG: Measuring inconsistency in meta-analyses. BMJ 2003;327:557-560.

18 Han HJ, Russo J, Kohwi Y, Kohwi-Shigematsu T: SATB1 reprogrammes gene expression to promote breast tumour growth and metastasis. Nature 2008;452:187-193.

19 Laurinavicius A, Laurinaviciene A, Ostapenko V, Dasevicius D, Jarmalaite S, Lazutka J: Immunohistochemistry profiles of breast ductal carcinoma: factor analysis of digital image analysis data. Diagn Pathol 2012;7:27.

20 Tan XH ,Cen H, Guo BP, Chen C, Lao YC: The SATB1 gene expression in breast cancer and the clinical significance. J Pract Med 2012;28:83-85.

21 Yang WH, Zhong SJ, Duan LF, Huang YX, Mi XJ: Detection of HER-2 gene amplification in invasive breast ductal carcinoma by fluorescence in situ hybridization and its relationship with SATB1 and HR proteins expressions. Chin Matern Child Health Care 2015;30:3884-3887.

22 Zhang S, Gao X, Ma Y, Jiang J, Dai Z, Yin X, Min W, Hui W, Wang B: Expression and significance of SATB1 in the development of breast cancer. Genet Mol Res 2015;14:3309-3317.

23 Zhang Y, Chen LJ, Liu YY: The expression of SATB1 and BRMS1 in breast invasive ductal carcinoma and their correlations with lymphatic metastasis. Guangdong Med J 2015;36:532-537.

24 Zhang Y, Hu GQ Liu YY: Expression of the special AT rich sequence binding protein in breast carcinoma and its clinical use. Acta Academiae Medicinae Xuzhou 2014;34:421-425.

25 Zhuang JL, Tian YW, Xu RY, Su ZJ: Expressions of SATB1 and Bcl-2 in invasive breast cancer and their clinical significance. Chin J Breast Dis(Electronic Edition) 2010;4:566-580.

26 Zhang L, Long X: Association of BRCA1 promoter methylation with sporadic breast cancers: Evidence from 40 studies. Sci Rep 2015;5:17869.

27 Ordinario E, Han HJ, Furuta S, Heiser LM, Jakkula LR, Rodier F, Spellman PT, Campisi J, Gray JW, Bissell MJ, Kohwi Y, Kohwi-Shigematsu T: ATM suppresses SATB1-induced malignant progression in breast epithelial cells. PLoS One 2012;7:e51786.

28 Kohwi-Shigematsu T, Poterlowicz K, Ordinario E, Han HJ, Botchkarev V, Kohwi Y: Genome Organizing Function of SATB1 in Tumor Progression. Semin Cancer Biol 2013;23:72-79.

29 Zheng J: Is SATB1 a master regulator in breast cancer growth and metastasis? Womens Health (Lond Engl) 2008;4:329-332.

30 Kang Y, Siegel PM, Shu W, Drobnjak M, Kakonen SM, Cordon-Cardo C, Guise TA, Massague J: A multigenic program mediating breast cancer metastasis to bone. Cancer Cell 2003;3:537-549.

31 Minn AJ, Gupta GP, Siegel PM, Bos PD, Shu W, Giri DD, Viale A, Olshen AB, Gerald WL, Massague J: Genes that mediate breast cancer metastasis to lung. Nature 2005;436:518-524.

32 Yuan X, Wu H, Xu H, Han N, Chu Q, Yu S, Chen Y, Wu K: Meta-analysis reveals the correlation of Notch signaling with non-small cell lung cancer progression and prognosis. Sci Rep 2015;5:10338.

33 Han J, Hendzel MJ, Allalunis-Turner J: Notch signaling as a therapeutic target for breast cancer treatment? Breast Cancer Res 2011;13:210.

34 Sun DW, Zhang HD, Mao L, Mao CF, Chen W, Cui M, Ma R, Cao HX, Jing CW, Wang Z, Wu JZ, Tang JH: Luteolin Inhibits Breast Cancer Development and Progression In Vitro and In Vivo by Suppressing Notch Signaling and Regulating MiRNAs. Cell Physiol Biochem 2015;37:1693-1711.

35 Battula VL, Shi Y, Evans KW, Wang RY, Spaeth EL, Jacamo RO, Guerra R, Sahin AA, Marini FC, Hortobagyi G, Mani SA, Andreeff M: Ganglioside GD2 identifies breast cancer stem cells and promotes tumorigenesis. J Clin Invest 2012;122:2066-2078.

36 Tran DD, Corsa CA, Biswas H, Aft RL, Longmore GD: Temporal and spatial cooperation of Snail1 and Twist1 during epithelial-mesenchymal transition predicts for human breast cancer recurrence. Mol Cancer Res 2011;9:1644-1657.

37 Gao XY, Xue XH, Ma YN, Zhang SQ: Effect of baicalein on the expression of SATB1 in human breast cancer cells. Exp Ther Med 2015;9:1665-1669. 